\title{
OS DESAFIOS DE SER E ESTAR NA PROFISSÃO DOCENTE: REFLEXÕES DE UMA PROFESSORA SOBRE SUA TRAJETÓRIA PROFISSIONAL
}

\section{- ANDRÉA SOUZA DE ALBUQUERQUE}

Universidade Federal do Pará

\section{TADEU OLIVER GONÇALVES}

Universidade Federal do Pará

RESUMO Este artigo parte de indagação sobre como reflexões propostas em relatos autobiográficos realizados por docentes ajudam a melhor compreender a trajetória profissional docente. 0 estudo toma por base o breve relato da trajetória profissional de uma professora do Programa de Pós-Graduação stricto sensu em Educação em Ciências e Matemática da Universidade Federal do Pará. O tratamento metodológico da pesquisa foi de tipo qualitativo. Para tanto, foram utilizados o relato autobiográfico e a análise das experiências de formação e de ensino. 0 relato autobiográfico possibilitou recuperar as memórias, desde a formação inicial, em dois cursos superiores: Bacharelado em Direito e Licenciatura em Pedagogia, marcados ainda pelo modelo da racionalidade técnica. Porém, ao recuperar e relatar o modelo formativo, foi possivel identificar determinados aspectos e considerá-los como substrato importante para a configuração da professora como profissional. As análises realizadas evidenciaram que, no decorrer da formação inicial e do exercício da profissão docente, determinados aspectos foram se modificando, como: a postura docente; a preocupação com a metodologia de ensino que melhor se adequasse à faixa etária e à necessidades dos alunos; a relação e o diálogo estabelecidos com os alunos e com outros professores; as experiências adquiridas nos diferentes campos de trabalho, da educação básica ao ensino superior; e as contribuições para o processo de reflexão sobre a ação, advindas com o processo de formação continuada, na busca pela autonomia do trabalho docente com vistas à melhoria do ensino. Neste sentido, os estudos autobiográficos auxiliam processos formativos de reflexão e possibilitam modificar as práticas docentes, desde que realizados em processos sistematizados e contínuos de estudos e intervenções.

Palavras-chave: Ensino. Formação docente. Professor reflexivo. 

PROFESSIONAL TRAJECTORY

This article starts from the question about how reflections proposed in autobiographical reports by teachers help to better understand the professional trajectory of teachers. he study is based on the brief report of the professional trajectory of a teacher of the Post-Graduation Program stricto sensu in Education in Science and Mathematics of the Federal University of Pará. The methodological treatment of the research was of qualitative type, for which we used the autobiographical report and the analysis of the training and teaching experiences. The autobiographical account made it possible to recover the memories from the initial formation in two higher courses, Bachelor of Law and Licenciatura in Pedagogy, still marked by the model of technical rationality. However, when retrieving and reporting the training model, it was possible to identify certain aspects and consider them as an important substrate for the teacher's configuration as a professional. The analyzes showed that, during the initial training and the exercise of the teaching profession, certain aspects were modified, such as: the teaching position, the concern with the teaching methodology that best suited the age group and students' needs; the relationship and dialogue established with students and other teachers; the experiences acquired in the different fields of work, from basic education to higher education; and the contributions to the process of reflection on the action, resulting from the process of continuous training, in the quest for the autonomy of teaching work with a view to improving teaching. In this sense, the autobiographical studies help formative processes of reflection and make it possible to modify teaching practices, provided that they are carried out in systematized and continuous processes of studies and interventions.

Keywords: Teaching. Teacher training. Reflective teacher.

\section{RESUMEN LOS DESAFÍOS DE SER Y ESTAR EN LA PROFESIÓN DOCENTE: REFLEXIONES DE UNA PROFESORA SOBRE SU TRAYECTORIA PROFESIONAL}

Este artículo parte de la indagación sobre cómo reflexiones propuestas en relatos autobiográficos realizados por docentes ayudan a comprender mejor la trayectoria profesional docente. El estudio se basa en el breve relato de la trayectoria profesional de una profesora 
del Programa de Postgrado stricto sensu en Educación en Ciencias y Matemáticas de la Universidad Federal de Pará. El tratamiento metodológico de la investigación fue de tipo cualitativo, para lo cual se utilizaron el relato autobiográfico y el análisis de las experiencias de formación y de enseñanza. El relato autobiográfico posibilitó recuperar las memorias desde la formación inicial en dos cursos superiores, Bachillerato en Derecho y Licenciatura en Pedagogía, marcados aún por el modelo de la racionalidad técnica. Sin embargo, al recuperar e informar el modelo formativo, fue posible identificar determinados aspectos y considerarlos como sustrato importante para la configuración de la profesora como profesional. Los análisis realizados evidenciaron que, en el curso de la formación inicial y del ejercicio de la profesión docente, determinados aspectos se fueron modificando, como: la postura docente; la preocupación con la metodología de enseñanza que mejor se adecuara a la franja etaria y necesidades de los alumnos; la relación y el diálogo establecidos con los alumnos y con otros profesores; las experiencias adquiridas en los diferentes campos de trabajo, de la educación básica a la enseñanza superior; y las contribuciones al proceso de reflexión sobre la acción, surgidas con el proceso de formación continuada, en la búsqueda de la autonomía del trabajo docente con miras a la mejora de la enseñanza. En este sentido, los estudios autobiográficos auxilian procesos formativos de reflexión y posibilitan modificar las prácticas docentes, desde que realizados en procesos sistematizados y continuos de estudios e intervenciones.

Palabras Clave: Enseñanza. Formación docente. Profesor reflexivo.

\section{Introdução}

Este texto foi escrito a partir da indagação inicial proposta na disciplina: "Aprendizagem para a docência e conhecimentos profissionais para a docência em ciência e matemática", ofertada pela Rede Amazônica de Educação em Ciências e Matemática (REAMEC), no Programa de Pós-Graduação em Educação em Ciências e Matemática, da Universidade Federal do Pará (PPGECM/UFPA). A indagação inicial do estudo foi: de que forma as reflexões propostas em relatos autobiográficos realizados por docentes ajudam a melhor compreender sua prática docente em sala de aula? Para tanto, foram tomadas como base as experiências de ensino vivenciadas como professora, desde minhas primeiras experiências na educação infantil até o presente momento, como professora do ensino superior. o propósito deste estudo é melhor compreender a trajetória profissional e acadêmica, com base no resgate do percurso profissional e acadêmico.

Neste sentido, a partir das narrativas de vida e do resgate histórico do percurso acadêmico e profissional, procuro desenvolver os desafios enfrentados no início da carreira docente, as experiências adquiridas na práti- 
ca em sala de aula, assim como refletir sobre o processo de construção da própria identidade do ser professora. Dessa forma, tomo por base metodológica o relato autobiográfico como metodologia de pesquisa-formação, viabilizando construir novas possibilidades de compreensão do ser professor e da prática desenvolvida em sala de aula.

Diante da temática inicial proposta, foram selecionadas, para fins de escrita do artigo, os autores referência da disciplina: Contreras (2002), Zeichner (1993), Schnetzler (2002; 2003), Huberman (1992); Corrêa (2013), Nóvoa (1992), Josso (2010), Bueno (2002) e Bueno et al (2006), sendo os dois últimos as referências que tratam da metodologia de pesquisa autobiográfica, portanto, aquela a que me proponho neste trabalho para a análise das reflexões vivenciadas e descritas sobre o processo de formação e de experiência profissional no ensino.

Nesta perspectiva, o texto se configura entre relatos de formação inicial e os desafios enfrentados neste início de carreira. Em segui$\mathrm{da}$, detenho-me nas reflexões sobre as experiências adquiridas na prática de sala de aula e os processos de formação continuada, além da construção da identidade docente, com reflexões que chegam a delinear indícios sobre como me constituí na professora que sou e as novas possibilidades de compreensão, já munida do entendimento do ser professor e das práticas desenvolvidas em sala de aula.

\section{O método autobiográfico}

Segundo Bueno (2002), o método autobiográfico e os estudos com histórias de vida de professores passam a ser considerados, a partir da década de 1980, como um redirecionamento dos estudos sobre a formação de professores, com ênfase na pessoa do professor, que passou a ser considerado em sua condição subjetiva. Isso veio a favorecer o surgimento de obras e estudos sobre a vida, as carreiras e os percursos profissionais dos docentes (NÓVOA, 1992).

Bueno (2002) busca ainda compreender o motivou da adesão a este tipo de abordagem autobiográfica, com a análise das rupturas ocorridas no campo das Ciências Humanas devido a esta nova percepção de método de estudo. Além disso, considera as suas especificidades, a relação da história social e individual, ressaltando aspectos como: a necessidade de construção de teoria sobre a formação de adultos; as potencialidades do estudo e abordagens; as dificuldades metodológicas; a diversidade de usos e a imaturidade e juventude da área.

Bueno et al (2006) também realizaram análise da produção metodológica da história de vida e autobiografias, em investigações sobre a formação de professores e a profissão docente no Brasil, entre 1985 a 2003. Em suas reflexões, apontam para o crescimento desta metodologia, principalmente na década de 1990 , contribuindo para renovar a pesquisa educacional, a partir de estudos sobre profissão, profissionalização e identidades docentes. (BUENO et al, 2006, p. 402).

Bueno et al (2006) destacam ainda que os procedimentos autobiográficos, no que diz respeito às narrativas em primeira pessoa em geral utilizadas para oferecer depoimentos sobre a formação e a trajetória profissional de professores -, possuem o mérito de fazer ecoar as vozes dos sujeitos do campo educacional, constituindo-se em casos isolados, abertos a interpretações sem fim, à espera de que os leitores cheguem, ao que Ferrarotti (1988, p. 26 apud BUENO et al, 2006, p. 404) descreve: “[...] o nosso sistema social encontra-se integralmente em cada um dos nossos atos, em cada um dos nossos sonhos, delírios, obras, comportamentos. E a história deste sistema está contida por inteiro na história da nossa vida individual". 
Outra autora que contribui de forma significativa para a metodologia de relatos biográficos docentes, como metodologia de formação de professora, é Josso (2010). Ela nos leva a analisar o trabalho docente a partir da própria história de vida deste, com centralidade na bagagem experiencial na formação, um olhar atento e reflexivo do indivíduo sobre si mesmo. Com isso, a abordagem de formação pode auxiliar na tomada de consciência sobre as experiências que cada um vive, podendo-se tirar lições e aprender. 0 caminho proposto para os relatos é a narrativa.

Josso (2010) é a precursora da aplicação das narrativas autobiográficas, dos relatos de história de vida relacionados à problemática da formação continuada de professores e como instrumentos da metodologia de pesquisa-formação. 0 relato das experiências é a via de acesso ao processo de formação. Assim, ao relacionar os fatos, acontecimentos e situações de sua trajetória de vida profissional e acadêmica - e ao processo de conhecimento construído intelectualmente -, demonstra que o sujeito aprendente e cognoscente é que está em formação, orientando a pesquisa-formação.

Josso (2010) defende que, na universidade, a metodologia da pesquisa-formação deve ser aplicada a cursos de formação continuada, uma vez que pode oferecer aprendizagem que serve de base para a formação intelectual docente, entendida como desenvolvimento das capacidades reflexivas, integrando referenciais de pensamento e ação, da capacidade de observações e de investigação subordinada à melhoria da qualidade de vida.

A abertura para a própria experiência é um dos caminhos da autodireção. A tomada de consciência sobre as experiências formadoras desvela o potencial do sujeito que emerge como um referencial experiencial. Este é atributo singular, considerado como pressuposto constitutivo estruturante da maneira de ser do sujeito, quando alicerça suas ideias e pensamentos e se exterioriza nas intervenções que manifesta em suas ações, relações e no contexto em que se encontra.

Nesta perspectiva metodológica, procuro elucidar, a partir das contribuições da pesquisa-formação autobiográfica, de que forma essas reflexões podem ajudam a melhor explicar/ compreender a prática docente em sala de aula, na busca do que foi formador no meu processo acadêmico e profissional, visando a identificar os desafios enfrentados no início da carreira docente, as experiências adquiridas na prática em sala de aula e o processo de construção da minha própria identidade de ser professora. Vejamos agora o breve relato da trajetória de formação inicial da docente e as reflexões sobre os desafios enfrentados no início da carreira.

\section{Relato da trajetória de formação inicial e os desafios do inicio da carreira}

O relato descreve a trajetória acadêmica e profissional da docente, no âmbito do curso de Licenciatura em Pedagogia e no Bacharelado em Direito, com o propósito de pontuar e refletir de forma mais sistemática e formativa, por meio da narrativa, sobre a questão: de que forma as reflexões propostas em relatos autobiográficos realizados por docentes ajudam a melhor compreender sua prática docente em sala de aula? O que me leva necessariamente a refletir sobre meu próprio processo de construção da identidade profissional enquanto docente, marcada pelo tempo, pelas relações estabelecidas, pelos sabores e dissabores da docência.

Destaco inicialmente as dúvidas surgidas quando do ingresso ao ensino superior, o que levou a me inscrever e, para minha surpresa, 
ser aprovada na Licenciatura em Pedagogia, com habilitação em Administração Escolar, na Universidade do Estado do Pará (UEPA), e no curso de Bacharelado em Direito da Universidade da Amazônia (UNAMA), cursos muito concorridos à época. A pressão familiar levoume a cursar Direito, no período vespertino e, à noite, a Licenciatura em Pedagogia.

Destaco nestas reflexões que o curso de Bacharelado em Direito era voltado para a dedicação a um ritual acadêmico de aquisição de conhecimentos, cuja base era claramente o da racionalidade técnica, com estudos teóricos, aquisição de muitos livros, códigos, aulas tradicionais e professores dedicados à transmissão de grande quantidade de conteúdos, o que levava os alunos a gravarem, transcreverem, decorarem e copiarem tudo o que era dito ou abordado durante o momento das aulas, com calendários de avaliações escritas.

Este era o modelo com que eu, particularmente, e boa parte dos colegas já estávamos acostumados, presente desde o ensino médio, o que para mim não foi surpresa; dessa forma, apenas se reproduzia literalmente o que os professores ensinavam durante as aulas puramente teóricas, com estudos de muitos livros e autores, com adaptação às normas impostas pela academia.

O estágio em escritórios só foi possível, no último ano, com o encaminhamento da própria instituição. Nele, procurávamos relacionar o que havíamos estudado teoricamente durante quatro anos à realidade de vida das pessoas, do Tribunal de Justiça e a todo um padrão de trato para com as diferentes pessoas e situações, bem como outros modos de vestimenta, o uso de blazers, camisas de mangas cumpridas, sapatos de salto alto, o que no início me causou aversão, devido ao excesso de formalidade. No último ano, também nos deparamos com a necessidade de pesquisa para a elaboração do Trabalho de Conclusão do Curso
(TCC), que para mim foi de grande interesse; finalmente eu me deparava com questões relacionadas ao mundo real, problemas e busca de soluções por parte do Direito.

Diante deste relato, hoje identifico o modelo de formação do curso de Direito, durante anos nas instituições universitárias, como aquele da racionalidade técnica, que valoriza o conteúdo, a pesquisa, a investigação teórica, em detrimento da prática, que só será vista de forma superficial nos últimos anos do curso.

Partindo desta premissa, os professores da área do Direito, em geral advogados sem a formação pedagógica, geralmente apenas graduados, mas renomados no mundo da prática, concebem o ensino como um momento de aprendizado da teoria, pura e simples, dos livros, portanto, teórico. Após conhecerem parte da teoria, os futuros profissionais, chamados de "operadores do direito" irão aplicá-la com o objetivo de encontrar a melhor solução ao caso, considerados assim como técnicos.

Esta concepção toma por base o que PérezGomez (1992) sinaliza como a racionalidade técnica, com origem no positivismo, que serviu de referência para a educação e a socialização dos profissionais de todas as áreas, durante o século XX. Assim, destaca que a atividade profissional é instrumental, com o objetivo de resolver problemas, mediante a aplicação rigorosa de teorias e técnicas científicas.

Na prática, com base nesta concepção, são criadas as divisões do trabalho, gerando o isolamento dos profissionais, a separação pessoal e institucional entre investigação (teóricos) e prática (técnicos), esquecendo-se o caráter moral e político da ação profissional humana. O profissional, nesta perspectiva, é visto como alguém que deve aplicar os conhecimentos teóricos aprendidos, sem levar em consideração que cada situação de vida e os problemas concretos têm seu contexto, sendo singulares e únicos, diferenciados - não podendo ser re- 
sumidos a problemas meramente instrumentais, com a aplicação de meios e procedimentos teóricos.

Os problemas enfrentados pelos alunos de Direito, quando se deparam com a prática, são inúmeros, pois não conseguem ouvir o cliente, têm dificuldade de compreender o contexto social e político em que vivem, querendo apenas obedecer ao estritamente legal, o que diz a norma, como se fosse possivel abarcar a realidade em códigos ou normas restritas a determinado período histórico de elaboração. 0 currículo também pouco discute questões sobre Ética, Meio Ambiente, Diversidade, dentre outras questões importantes para que o profissional possa ter um olhar mais abrangente sobre a realidade e que the possibilite refletir, fazer inferências, argumentar.

Refletir sobre o processo de ensino no curso de Direito, a que os profissionais desta área estão sujeitos, ganha outro significado na medida em que me ajuda a melhor compreender que este modelo já não é suficiente para desenvolver as competências necessárias para a atuação de um profissional da área do Direito ou de qualquer área, pois os casos específicos que irá defender em sua jornada requerem a reflexão crítica, a argumentação, o debate. Além disso, cabe investir na qualificação do corpo docente, pois poucos eram aqueles que tinham alguma formação pedagógica e/ou em outra área do conhecimento, o que dificultava a adoção de metodologias de ensino diferenciadas - sendo apenas dois entre os docentes durante os cinco anos do curso.

Assim, ter vivenciado o curso, quase integralmente com aulas expositivas, fez-me explicar para mim mesma o quanto busco aplicar novas metodologias durante minha atuação em sala de aula. Pesquiso, converso com outros docentes, crio possibilidades metodológicas a fim de fomento à discussão, ao debate de ideias, à leitura, às proposições, aos posi- cionamentos dos alunos, de modo que acredito que a metodologia é o caminho para esta comunhão de saberes e para o maior interesse dos alunos no processo de ensino.

\section{A formação inicial no curso de licenciatura em pedagogia}

Por outro lado, no curso de Licenciatura em Pedagogia na UEPA, entrei em contato com outras concepções teóricas e diferentes abordagens no campo do conhecimento. As aulas e o currículo ainda tomavam por base a racionalidade técnica, pois o modelo ainda era o mesmo do curso de Direito, com disciplinas teóricas ministradas nos primeiros três anos e com o aluno passando a ir para o campo do estágio somente no último ano. Apesar da tentativa dos docentes da Universidade do Estado do Pará de propor, durante as aulas, temáticas diferenciadas, sobre a realidade social, a escola, os alunos, o processo de ensino-aprendizagem e o conhecimento humano, o modelo permanecia o mesmo.

Durante o curso, era notório o incentivo dos professores nas aulas, propondo leituras, discussão e debate das ideias dos autores, além da pesquisa e do questionamento sobre o que estava sendo colocado. Os docentes procuravam nos mostrar os referenciais teóricos que poderiam subsidiar a prática docente. Os estudos e pesquisas indicados nos levavam a adquirir certa autonomia no processo de estudos e reflexões sobre as possibilidades da prática.

As aulas eram interativas, os docentes propunham metodologias que incentivavam a participação, o diálogo, alguns alunos já atuavam na educação, o que nos levava a ouvir diferentes relatos de experiências. Havia propostas de saída ao campo, desenvolvimento de projetos em escolas públicas, organizações não governamentais, elaboração de relatórios, processo este que muito contribuiu 
para que pudéssemos verificar como estava a realidade educacional da Região Metropolitana de Belém.

Naquele momento, passei a ter contato mais próximo com a realidade da escola e as questões relacionadas ao papel do professor. Durante as vivências nos momentos de estágio, passei a refletir sobre o processo educacional, a aprendizagem, o ensino e principalmente sobre a formação inicial de professores para atuar na área. Isso me levou a compreender inclusive meu processo de formação, a importância de pesquisar, de refletir sobre diferentes formas de ensinar e aprender, e de considerar os diferentes saberes docentes, necessários para melhoria da qualidade da minha atuação enquanto professora.

Minha trajetória acadêmica foi marcada pela busca de experiências extracurriculares, ofertadas na Universidade ou em outros locais onde se ofereciam cursos, oficinas, palestras, seminários, encontros, congressos, dentre outros. Além disso, houve a participação em projetos de extensão no Projeto de Interiorização, realizado pela Universidade do Estado do Pará, na localidade de Mãe do Rio/ $\mathrm{PA}$, onde ministrei oficinas com o objetivo de contribuir para a divulgação do conhecimento em locais carentes de cursos de formação para professores. As experiências possibilitaram melhor compreender a relação entre os teóricos estudados e a prática docente, o que enriqueceu a forma de pensar sobre o processo educacional.

Cabe destacar que ambas as formações iniciais, tanto em Pedagogia quanto em Direito, tomam por base o modelo dominante, da racionalidade técnica, o que, de acordo com Contreras (2002), precisa ser revisto, já que se baseia na ideia de que a prática profissional docente consiste na solução instrumental de problemas por meio da aplicação de um conhecimento teórico e técnico, previamente disponivel, o qual procede da pesquisa científica. A prática seria a aplicação inteligente, pura e simples, do conhecimento teórico aos problemas enfrentados por um profissional, seja do professor em sala de aula, seja de um advogado no contexto do exercício da advocacia, no intuito de encontrar uma solução satisfatória.

Entretanto, os contextos aqui se diferenciam, no que concerne à concepção de profissionais. Os advogados possuem todos os requisitos indispensáveis para serem considerados como profissionais, como o exercício do trabalho autônomo, com um conjunto de normas e valores assegurados pela associação profissional, a Ordem dos Advogados do Brasil (OAB), em âmbito nacional, que lhes assegura direitos no exercício profissional, com um corpo de conhecimentos e técnicas sedimentados, o que lhes possibilita agir com autonomia em sua atividade profissional.

Caso diferente é o dos professores que não possuem uma associação profissional, nem estatutos com normas e valores que lhes garantam direitos. Estão submetidos à chancela do Estado, o que prejudica sobremaneira sua autonomia, devendo aplicar os currículos e os processos de avaliação externos prescritos por especialistas que, às vezes, nunca atuaram em sala de aula, o que por sua vez causa sérios conflitos e desgastes. 0 processo de formação docente também é alvo de constantes mudanças, fator capaz de prejudicar a configuração de um corpo de conhecimentos e técnicas definidas, necessárias à atuação docente.

Voltando à questão inicial de pesquisa, passo a refletir sobre de que forma esta narrativa pode contribuir para explicar minha prática docente. Esta recordação é bastante reveladora, em minhas memórias, pois foi a partir da postura dos docentes, em sala de aula, das contribuições dos autores, das possibilidades de discussão e de pesquisa que fui me cons- 
tituindo na professora que sou hoje. A minha formação inicial na Licenciatura em Pedagogia contribuiu de forma significativa para minha atuação, minhas concepções e a compreensão da dimensão do papel social do professor, que foram construídas a partir das experiências propostas pela Universidade.

Diferentemente do que aconteceu no curso de Direito, quando houve momentos em que desejei desistir, pois as posturas dos professores eram distantes - não gostavam de interrupções ou de questionamentos, inviabilizavam o diálogo e a proposição de outras ideias, o que de certa forma me angustiava. Apesar disso, concluí o curso no tempo devido.

Neste momento, ao escrever e recuperar os modelos formativos vivenciados, foi possivel identificar determinadas diferenças importantes para a constituição da identidade profissional de ser professora, pois ter sido aluna de Licenciatura em Pedagogia me fez compreender a necessidade de considerar determinados aspectos importantes, durante a formação inicial docente, que se tornaram pontos diferenciais: a postura ética e comprometida dos professores com o processo de ensino; as propostas metodológicas diferenciadas adotadas pelos docentes; as diferentes proposições teóricas debatidas e discutidas em sala de aula; e as experiências dos projetos de extensão vivenciados na própria instituição formadora, a universidade.

A consideração da prática profissional docente como aplicação de procedimentos e meios técnicos para conseguir determinados fins pode até certo ponto servir aos fins da área do bacharelado, porém, no campo das licenciaturas, este modelo já não contribui de forma significativa para a melhoria do processo de ensino, pelos motivos que busco melhor compreender a partir das reflexões sobre o início da atuação como professora, que destaco no relato a seguir.

\section{Os desafios do início da carreira docente}

No último ano do curso de Pedagogia, fui contratada por uma escola particular para o ensino na educação infantil. Foi minha primeira experiência em sala de aula. Tudo para mim era novo, os alunos tinham três anos de idade - como lidar com essa faixa etária? Foi desafiador. o conteúdo a ser desenvolvido estava em minhas mãos, mas o que fazer com ele, como desenvolver? Aflita em busca de respostas e sem saber muito bem como agir, fui em busca de pessoas mais experientes, como uma colega da faculdade, que já atuava na educação infantil e the perguntei como agir. Ela me explicou as formas como eu poderia fazer o planejamento e criar atividades a serem desenvolvidas com os alunos.

A colega, mais experiente, orientou-me sobre as atividades, deixar as crianças se expressarem, descobrirem a novidade. Em seguida, eu deveria direcionar as atividades para os objetivos propostos, e, aos poucos, fui compreendendo o que ela tentava me dizer, mas, como as palavras muitas vezes não alcançam determinadas dimensões, fui aprendendo pela tentativa e pelos erros. Quais as atividades preparar para os alunos nesta faixa etária? Comprava livros para tentar entender melhor o que a formação inicial não havia ensinado sobre como agir na prática docente. Fui então compreendendo como deveria agir, e meus alunos se tornaram crianças participativas nas atividades, dentro e fora da sala de aula.

Ao revelar este contexto de atuação inicial, reporto-me a Corrêa (2013), para quem o início da docência é marcado por transformações e dificuldades, uma vez que o professor se depara com a discrepância entre as expectativas do iniciante e a realidade do trabalho, sobre a qual Kramer (1974 apud CORRÊA, 2013), cunhou a expressão: "choque de realidade". 
Vivenciei claramente este choque, pois a realidade se mostrou mais desafiadora e as teorias da academia não puderam prever 0 quanto. Isso me levou a buscar, pesquisar, dialogar com outros profissionais mais experientes.

Veenman (1988 apud CORRÊA, 2013) aponta em sua investigação que a indisciplina aparece entre as dificuldades mais apontadas por professores em início de carreira. Esta dificuldade ficou clara durante minha primeira experiência docente, o que me mobilizou a planejar diversas atividades para que os alunos estivessem tão envolvidos no trabalho que não teriam tempo para a indisciplina, algo que surgiu do diálogo com outros docentes.

Neste sentido, também me reporto a Huberman (1992), que investigou sobre o ciclo de vida dos professores e identificou as etapas da carreira docente. A primeira etapa configurase como o início ou a entrada na carreira, ocorre nos três primeiros anos da docência, sendo a fase da "descoberta" e da "sobrevivência", relacionada com a expressão "choque de realidade". É a fase caracterizada pelo tatear constante do professor, com preocupação consigo mesmo e o descompasso entre os ideais do início e a realidade que encontra na escola.

Apesar da importância desses estudos, cabe destacar suas limitações, pois tendem a simplificar o que ocorre na realidade, ao desconsiderarem outros aspectos, como as experiências singulares, o significado que os docentes atribuem às experiências, frustrações vividas, dentre outras, que podem influenciar a vida profissional docente.

Outro momento importante do início da carreira docente foi o contrato com a Secretaria Estadual de Educação para ministrar aulas de língua estrangeira na rede estadual, pois havia carência deste profissional e os que tinham formação pedagógica e dominavam o idioma foram contratados para ministrar aulas nas escolas de ensino fundamental e médio, como foi o meu caso.

A experiência vivenciada foi de fundamental importância para minha formação, pois os alunos eram adolescentes, por isso me perguntava: como lidar com adolescentes? Quais metodologias utilizar para chamar a atenção? Nas salas, havia cerca de 40 alunos, para os quais planejei as aulas no sentido de fazê-los compreender a importância do estudo da língua estrangeira, de outra cultura. Enfim, procurei chamar a atenção desses adolescentes para o diálogo, procurando ouvi-los inicialmente. Acredito que este tenha sido o ponto chave da relação de diálogo e respeito que passei a estabelecer com os alunos - fato este que causou até certo mal-estar entre os professores mais experientes da escola que, na sala dos professores, perguntavam-me como eu tinha conseguido me relacionar bem com aqueles alunos. Criticavam a postura dos alunos, mas em nenhum momento procuraram ouvi-los.

Huberman (1992) explica esta etapa como a fase de descoberta, momento em que o docente faz experimentações e tem certa vaidade por ter sua própria sala de aula, seus alunos, por fazer parte de um grupo profissional, configurando-se como um período de aprendizagens, com desenvolvimento do conhecimento profissional e a busca do equilíbrio entre o pessoal e o profissional.

Era minha fase de descobertas. Passei a fazer experimentações com diversas turmas, diferentes séries, maior domínio da classe e tive certa vaidade por ter minha própria turma, meus alunos, por fazer parte de um grupo profissional, com trabalho em uma escola determinada. Isso de fato se configurou como um período de aprendizagens, com maior desenvolvimento do conhecimento profissional.

Não há linearidade nesses percursos, pois as características apresentadas pelos autores 
no início da carreira podem se manifestar a qualquer tempo da carreira docente, de acordo com a situação de novidade enfrentada, como a mudança de escola, de turmas, dos alunos.

Corrêa (2013) destaca que o início da docência é um momento instável, de insegurança, mas proporciona também vivências desafiadoras, criadoras de novas relações profissionais, de redefinição de crenças, com suas tensões e desequilíbrios.

Apesar de já estar desenvolvendo com maior segurança o ofício, considero que passei por determinadas dificuldades como iniciante, dentre as quais destaco: a insegurança no que concerne ao domínio do conteúdo a ser ensinado, afinal eu não detinha o conhecimento pleno da língua estrangeira, nem era da área de Letras, o que comprometia determinados conteúdos; a solidão da carreira, pois os professores mais experientes tendem a rejeitar as inovações propostas por professores iniciantes; a fiscalização pela gestão da escola, sem proporcionar qualquer contribuição ao trabalho docente; e a falta de condições estruturais da escola.

Em sua pesquisa, Corrêa (2013) destaca que a carência do domínio do conteúdo por parte do docente também se relaciona com a dificuldade deste em propor inovações didático -pedagógicas e reelaborar conceitualmente o conteúdo e promover um ensino relevante aos alunos.

É ao ingressar nas escolas, nas salas de aula, que o professor se depara com a realidade e com o processo de ensino, pois na Universidade a relação teoria-prática ainda está distante. 0 curso de Pedagogia ofereceu anos de estudos teóricos com poucas experiências sobre a prática docente, o que afeta diretamente o professor iniciante, pois, ao se deparar com a realidade da escola, sente-se despreparado e não tem com quem compartilhar suas dúvidas e angústias.
As escolas, por sua vez, ao receberem os docentes inexperientes, encarregam-nos das salas de aula consideradas mais problemáticas, com alunos indisciplinados, e o controle de classe os classifica como bons ou maus docentes, desconsiderando o domínio que estes possam tem do conteúdo a ser ministrado. De modo geral, o docente, em busca de manter a disciplina e de atender ao que se espera dele, utiliza-se de métodos tradicionais, adotando posturas rígidas e de extrema autoridade para com os alunos. As escolas e os docentes mais experientes não acolhem os professores novatos, para que estes possam refletir e ultrapassar as dificuldades do início da carreira. Ao contrário, parece que até nos incentivam a desistir da carreira (CORRÊA, 2013).

A falta de domínio do conteúdo, aliada à insegurança, leva o professor iniciante a adotar, muitas vezes, de forma acrítica o livro didático, engessando a própria prática e aprisionando-o diariamente às consultas e à reprodução de seu conteúdo, levando-o à dependência e à não reflexão sobre o conteúdo, gerando um ensino passivo, técnico e limitado (CORRÊA, 2013).

Um segundo dilema é o isolamento do docente recém-chegado à escola, cujo cenário o posiciona como novato, o que leva a um estado de insegurança e de submissão, pois se sente vigiado por todos no ambiente escolar. De modo que, para ser aceito pelo grupo, faz imitações acríticas das condutas de outros professores, mais experientes, e obedece a normas e regras estabelecidas na escola. Isso caracteriza a vivência de um momento solitário, sem a colaboração de seus pares, o que afeta o processo de construção identitária docente e de não pertencimento ao grupo. Neste contexto, as escolas deveriam se organizar para acolher os novos docentes, para que estes possam refletir e ultrapassar as dificuldades do início da carreira docente. A aprendizagem com os pares é uma fonte importante para o fortale- 
cimento do grupo e para o desenvolvimento formativo docente (CORRÊA, 2013).

\section{Novos campos da atuação profissional aliada à formação continuada}

Em 2000, fui aprovada no concurso público da Secretaria Municipal de Educação de Belém, como coordenadora pedagógica, e passei a atuar nas escolas, agora com a equipe de gestão. Este redimensionamento foi importante na medida em que me possibilitaria ter uma postura diferente de outras coordenações que eu havia vivenciado, pois, ao invés de fiscalizar os professores, poderia observar suas práticas e procurar contribuir com suas metodologias, sugerindo, planejando, propondo encontros e reuniões pedagógicas.

Entretanto, senti, no decorrer do trabalho, a necessidade de voltar à universidade. Cursei a especialização em Gestão Escolar na Universidade do Estado do Pará, o que me deu subsídios teóricos importantes para compreender melhor o sistema de ensino, a relação escola e políticas públicas educacionais, bem como auxiliar os docentes nas formações continuadas, com estudos nas Horas Pedagógicas (HP) no espaço da escola - espaços/momentos que existem na Rede Municipal de Educação, em que a coordenação pedagógica da escola orienta os estudos dos professores.

Ao finalizar a especialização e no intuito de continuar os estudos, inscrevi-me no processo de seleção ao Mestrado na UEPA e fui aprovada na linha de pesquisa Formação de Professores, com foco na Educação de Jovens e Adultos.

Os conhecimentos proporcionados pelo processo de pesquisa no mestrado me fizeram refletir sobre a formação docente e despertar a mudança de postura frente ao processo de ensino. Porém, ao retornar à escola, deparei-me com um sistema educacional burocrático, o que se torna um problema, segundo Schön (1992), pois o professor, ao propor a reflexão em seus processos de ensino, irá se deparar com a burocracia do sistema escolar, com planos de aulas e quantitativos de informações que devem ser transmitidas num determinado tempo; uma iniciativa que ameace esta visão do conhecimento entra em conflito com a burocracia da escola. Assim, o desenvolvimento de práticas reflexivas requer a integração ao contexto institucional, e o professor precisará estar atento à burocracia que a escola tende a perpetuar.

Ao retornar do mestrado, fui lotada na escola, mas logo fui convidada a ministrar um curso de formação continuada aos coordenadores pedagógicos e professores da Rede Municipal de Educação. Isso me deixou muito feliz inicialmente, pois eu poderia colocar em prática tudo o que havia aprendido no mestrado. Porém, as dificuldades eram inúmeras, já que a Secretaria não propiciava o suporte necessário para desenvolver os processos de formação continuada. As formações tinham como base o modelo de racionalidade técnica, que infelizmente desconsiderava a necessidade de discussão do processo de ensino que os docentes vivenciavam, buscando apenas ensinar-lhes novas metodologias de trabalho.

Schnetzler (2002) destaca importantes contribuições acerca da formação continuada de professores, válida para qualquer processo que envolva outros docentes, uma vez que afirma que grande parte dos cursos propostos nos programas de formação continuada não leva em consideração problemas apontados pelos docentes. Além disso, contam com poucas horas de cursos, de modo que, ao terminar, cada docente retorna ao trabalho, não considerando os problemas vivenciados no contexto concreto de produção do ensino. Assim, mesmo que tenha vontade de aplicar o que foi levantado, o docente estará sozinho, sem o outro para trocar experiências, discutir dile- 
mas, e inseguranças, ao tentar algo novo.

Toda ação docente é pautada por concepções sobre o ensino, a aprendizagem, o aluno, a escola e crenças que nem sempre são conscientes para o docente. Assim, mudanças e inovações na prática de ensino requerem do professor desconstruir e reconstruir concepções arraigadas. Isso demanda tempo e condições, que não estão nas ações de formação continuada, geralmente curtas, esporádicas e descontínuas (SCHNETZLER, 2002).

A obrigatoriedade da presença do docente nos cursos contradiz, na raiz, o que se entende por formação continuada. Os programas de formação continuada constituem direito dos professores; a primeira condição a ser assegurada para sua ocorrência das formações continuadas é a organização do horário escolar, assegurando-se aos docentes horário livre e remuneração devida, bem como considerando-se os problemas da prática docente nos programas de formação continuada, algo que ocorre por meio da organização das formações em grupos de professores com necessidades e peculiaridades afins (SCHNETZLER, 2002).

As formações continuadas, para Schnetzler (2002), devem ser realizadas no ambiente escolar em que os docentes estarão mais comprometidos com o trabalho daquela instituição, o que significa o incentivo à criação de uma cultura docente que priorize o desenvolvimento profissional do professor no coletivo, com vistas à melhoria de sua prática pedagógica e de si mesmo, com o contato de novas aprendizagens e de sua relação com o outro, ou seja, alunos, professores, direção escolar, coordenação pedagógica.

Diante do que a autora considera como importante para a formação continuada, parto da minha experiência como formadora de professores e de coordenadores pedagógicos da Secretaria. Considero que as formações ofertadas são esporádicas, com tempo míni- mo, com propostas de discussões distantes da realidade dos docentes, pois são elaboradas com o que o grupo de formadores considera importante discutir, desconsiderando as situações de ensino nas escolas, o que precisa ser revisto com urgência.

Neste momento, procurei aliar as contribuições teóricas estudadas durante as pesquisas no mestrado com a atuação profissional, passando a desenvolver com maior segurança o ofício docente e com maior domínio do conteúdo, a partir do diálogo estabelecido entre professores, com objetivos e planos de ação comuns, e professores mais experientes, que se interessavam em participar de formações diferenciadas, fruto de referenciais teóricos e pesquisas no âmbito acadêmico. Porém, apesar das ricas experiências, aos poucos a proposta de gestão da secretaria se modificou, com corte de verbas para as formações.

\section{Professora do ensino superior: os desafios estão postos}

Naquele momento, ainda fui convidada a ministrar aulas no ensino superior, em uma instituição privada de ensino. Esta experiência é atualmente a que mais me envolve, pois ministro aulas para discentes do primeiro e segundo semestres dos cursos de Licenciaturas Integradas, nas disciplinas: a) Ética, Diversidade e Direitos Humanos; e b) Políticas Públicas e Legislação Educacional, dos cursos de Licenciatura em Letras, Geografia, História e Pedagogia.

O contato com os alunos no ensino superior tem sido de valiosa contribuição para perceber quem sou e como posso melhorar como docente, pois logo no primeiro dia de aula me apresento para a turma, relato meu percurso acadêmico e minha atuação profissional e que gosto muito de atuar como professora, que viso a contribuir com o percurso acadêmico deles como futuros docentes. Em segui- 
da, solicito que cada um deles se apresente: nome, idade, os motivos de escolha do curso, se trabalha e onde, no intuito de conhecer o outro, deixando o outro se revelar, escutando cada um, como pontuam suas dificuldades. Apresento ainda o que será tratado durante as aulas, o conteúdo, os textos, as abordagens, o processo de avaliação. Enfatizo sempre que a disciplina e a vida universitária e profissional exigem muita leitura, estudos, debates em grupos de discussão. No final do semestre letivo, realizo avaliações escritas para que eles possam avaliar meu trabalho.

O exercício da docência é um processo que requer o envolvimento de todos, do interesse, da motivação, e nós, professores, temos que ter este compromisso ético e social de, a um só tempo, contribuir com o desenvolvimento profissional de nossos alunos, proporcionando os conhecimentos teóricos necessários para sua atuação com qualidade, e tratá-los com o devido respeito, sem discriminar ou ter ideias preconceituosas sobre as atitudes deles. Ministrei aulas, sentia as dificuldades deles no processo de escrita, de organização das ideias, procurava ajudar, orientar - afinal, este é o meu papel: fazê-los continuar na caminhada, buscando superar as dificuldades, aprimorando-se sempre.

A prática docente deve ser um processo, uma reflexão sobre seus fins, o seu significado concreto nas situações complexas e conflituosas. Para Schön (apud CONTRERAS, 2002), o que gera, o que mobiliza a reflexão docente são os problemas, os casos práticos ou as dificuldades vivenciadas pelos professores no seu contexto. Já para Stenhouse (apud CONTRERAS, 2002), é a proposta curricular que o docente tem em mãos; este autor defende pesquisas do professor como produtor do currículo e não como simples aplicador de terceiros que ditam o que deve ser ensinado aos alunos. A reflexão depende dos conhecimentos profissionais que o docente possua, relacionados aos casos acumulados ao longo da experiência docente. A prática reflexiva, segundo Elliott (apud CONTRERAS, 2002), constitui-se em um processo dialético, de geração da prática a partir da teoria e desta para a prática.

Conforme destaca Corrêa (2013), o professor precisa construir relações de confiança para com seus alunos, mas só poderá fazê-lo se tiver claro o seu papel social, com domínio do conteúdo que convença os alunos e a si mesmo da relevância do que está sendo ministrado.

No final do semestre, sempre solicito aos alunos que façam uma avaliação escrita sobre o trabalho desenvolvido, a pertinência dos textos, as dificuldades sentidas, sugestões para a melhoria das aulas, e sempre recebo valiosas contribuições que, na medida do possivel, procuro agregar no semestre seguinte.

Zeichner (1993) defende em seus estudos a ideia do professor reflexivo de sua prática e que a formação de professores seja redimensionada, uma vez que o modelo da racionalidade técnica ainda presente nas universidades deve ser subvertido. Defende uma epistemologia da prática, em que o professor real e concreto que está atuando em sala de aula seja considerado, ouvido e, a partir deste, repensem-se os processos formativos.

Perez-Gómez (1992) defende o que chama de racionalidade prática, a qual requer que o professor ative seus recursos intelectuais, mesmo sob a pressão de diversas situações ocorridas no cotidiano escolar e da sala de aula, fazendo-o de forma ampla, a fim de elaborar sob seu ponto de vista um diagnóstico da situação, projetar estratégias de intervenção, e prever o que poderá ocorrer. Para compreender melhor este complexo processo de reflexão, é preciso distinguir três diferentes conceitos que integram o pensamento prático: conhecimento-na-ação; reflexão-na-ação e re- 
flexão sobre a ação, já apontadas por Schön e retomadas por Perez-Gómez.

0 conhecimento na ação refere-se ao saber fazer, fruto da experiência e da reflexão passadas já consolidadas. Além do conhecimento advindo de situação, mesmo quando a estamos realizando, estamos pensando sobre elas. Dessa forma, a reflexão-na-ação é um processo rico na formação do profissional prático. É no contato direto com a situação prática que se constroem novos conceitos, teorias, aprendizagens.

A reflexão sobre a ação é a análise que o indivíduo realiza posteriormente sobre o processo de sua própria ação. Quando utiliza o conhecimento para analisar e avaliar, com reflexões sobre a reconstrução realizada posteriormente, a ação realizada buscar compreender e reconstruir sua prática, componente essencial no processo de aprendizagem permanente da formação docente.

A partir do momento que o professor reflete sobre sua ação, passa a ser um investigador da sala de aula. Ao ter pleno conhecimento da estrutura da disciplina que ministra, reflete sobre o contexto peculiar da sala de aula, passa a construir uma teoria adequada à situação singular que vivencia na escola e ele mesmo elabora estratégias de ação adequadas à sua realidade específica.

Neste sentido, Perez-Goméz (apud CONTRERAS, 2002) defende que o profissional competente atua refletindo no momento de sua ação, configurando, assim, uma nova realidade, corrigindo e criando por meio do diálogo estabelecido com a realidade vivenciada. Deve aprender a construir novas estratégias de ação, transcendendo desta forma, o conhecimento emergente da racionalidade técnica. Com isso, a prática adquire um papel central no currículo como local de aprendizagem e de construção do pensamento prático do docente.
Porém, cabe enfatizar que as exigências crescentes, no trabalho docente, ocorrem, principalmente por parte das Secretarias de Educação e das Instituições de Ensino Superior, sem que se proporcionem a estes as condições objetivas para concretizar suas reflexões, estudos, produção de saberes e divulgação. As escolas, secretarias de educação e universidades não discutem nem implementam programas sérios de formação continuada e de melhorias das condições de trabalho. Sinto esse dilema cotidianamente, mas vou em busca de qualificação profissional sempre. Por isso, participei do processo seletivo para ingresso no Programa de Pós-Graduação stricto sensu em Educação em Ciências e Matemática, com foco no ensino, no âmbito da Universidade Federal do Pará.

Neste momento da carreira, destaco a etapa que Huberman (1992) caracteriza como as fases de estabilização e de diversificação, marcada pela estabilização e consolidação de um repertório pedagógico, além da construção de minha identidade profissional, com definição e afirmação do desejo de ser e estar na profissão docente, com comprometimento assumido e uma tomada de responsabilidade.

A atuação no ensino superior e na formação de outros docentes fizeram-me adotar a decisão de dedicar-me à profissão docente. A estabilidade significou constituir-me enquanto profissional autônoma no exercício profissional e encontrar um estilo próprio de atuação, com preocupações voltadas para os resultados do processo de ensino, com a aquisição de uma autoridade mais natural.

Huberman (1992) destaca que os professores desta fase falam de "flexibilidade", "prazer", referindo-se a sentimentos de tranquilidade e relaxamento no desempenho de suas funções docentes. A fase da experimentação e diversificação é o ciclo da carreira profissional entre os 7 e os 25 anos de experiência, que pode estar marcado por uma atitude geral de 
diversificação, mudança e ativismo, bem como uma atitude de revisão, cheia de interrogações peculiares da metade da carreira. Não se trata, portanto, de um ciclo homogêneo, no qual seja fácil caracterizar o pensamento e a conduta profissional do docente.

Quanto à atitude de diversificação, os professores lançam-se a uma série de experiências, trabalhando com novas metodologias, diversificando o material didático, experimentando novas formas de avaliação e modificando aspectos da sua prática.

Neste sentido, vejo-me um pouco nas características descritas pelo autor, uma vez que passei a desenvolver com maior segurança o ensino, superando as dificuldades de iniciante, atuando com mais segurança e domínio do conteúdo a ser ensinado, pois as disciplinas foram ministradas durante minha formação inicial. Considerando ainda que procuro estar sempre atualizada, no que se refere aos referenciais teóricos e à legislação, considero este momento como de superação da solidão sentida na carreira, pois no ensino superior e na instituição privada há necessidade de elaboração de projetos coletivos, possibilidades de trocas de experiências entre docentes e as inovações propostas são sempre discutidas no coletivo. As cobranças de cumprimento de carga horária e curricular persistem, bem como nas instituições públicas as condições de materiais didáticos e outras limitações dificultam o desenvolvimento da docência. Porém, reconfiguram-se de outra forma, já que neste percurso tomamos consciência dos limites e possibilidades da prática.

\section{Algumas reflexões para não concluir...}

O relato autobiográfico foi importante na medida em que me possibilitou recuperar meu percurso, desde a formação inicial nos cursos superiores de Bacharelado em Direito e Licenciatura em Pedagogia, marcados ainda pelo modelo da racionalidade técnica, com currículos voltados para a separação entre teoria e prática, que só se encontraram de forma superficial no fim dos cursos nas disciplinas de estágio.

Ao relatar o modelo formativo, foi possivel identificar determinados aspectos e considerá-los como substrato importante para a configuração minha identidade profissional como professora.

No decorrer da formação inicial e do exercício da profissão docente, determinados aspectos foram se modificando, dentre as quais destaco: a postura adotada em sala de aula, com base na reflexão sobre a ação, com adoção de avaliações do trabalho pontuadas pelos alunos; além de estudos e pesquisas sobre o trabalho docente, da preocupação constante com a metodologia de ensino adotada, que deve ser diferenciada de acordo com a faixa etária e as necessidades dos alunos; a relação e o diálogo estabelecidos com os alunos e outros professores; as experiências adquiridas nos diferentes campos de trabalho, da educação básica ao ensino superior; e as contribuições para o processo de reflexão sobre a ação, advindos com o processo de formação continuada, o que me impulsionou na contínua busca pela autonomia do trabalho docente com vistas à melhoria do ensino.

A partir de 2017 submeti-me ao processo de seleção e fui aprovado no Doutorado do Programa de Pós-Graduação em Educação em Ciências e Matemática - PPGECM da Universidade Federal do Pará - UFPA, na linha de pesquisa: percepção matemática, processos e raciocínios, saberes e valores, temáticas de meu interesse e que decorrem de minha formação acadêmica, sempre envolvida com a formação de professores. Além de agregar conhecimentos teóricos, o processo de pes- 
quisa do doutorado no ensino vai ao encontro de minha experiência profissional, pelo fato de ter atuado como professora da educação básica, na rede pública, professora de cursos de graduação em Licenciaturas de instituições privadas e de ter atuado como formadora na Diretoria de Educação da Secretaria Municipal de Educação - DIED/SEMEC, onde ministrei cursos de Formação Continuada para docentes da Rede Municipal de Educação. A pesquisa desenvolvida visa contribuir com os estudos sobre desenvolvimento profissional e formação continuada docente, com vistas à melhor compreensão do processo de ensino. Neste sentido venho desenvolvendo estudos, pesquisas, e aprofundando conhecimentos sobre o ensino, os referenciais teóricos e as possibilidades de adotar outros caminhos, como a ação sobre a ação.

Neste sentido, concordo com Schnetzler (2002), quando destaca a importância do incentivo às ações de formação continuada dos docentes, pois existe a necessidade de contínuo aprimoramento profissional do professor, que the possibilite reflexões críticas sobre sua prática pedagógica no ambiente do contexto de trabalho, assim como a melhoria do processo de ensino-aprendizagem.

Acredito que, apesar das dificuldades vivenciadas tanto no início quanto no percurso e que ainda hoje estão presentes quando ministro aulas no ensino superior, busco superá -las com estudos sobre metodologia ou conteúdo, com o diálogo com os alunos, por meio da busca por orientações na coordenação da instituição.

O exercício da docência é permeado por situações instáveis, de insegurança, mas proporciona também vivências desafiadoras, criadoras de novos saberes profissionais e pessoais, de redefinição de crenças, com suas tensões e desequilíbrios, os quais os docentes buscam resolver ainda de forma isolada, pois os pro- cessos formativos realizados pelo coletivo de docentes nos espaços escolares ou da IES ainda são raros e pontuais.

Nesta perspectiva, as reflexões propostas neste breve relato autobiográfico me ajudaram a compreender meu percurso formativo, desde minha formação inicial até os processos de formação continuada que venho desenvolvendo, sempre em busca de melhor desenvolvimento profissional para minha atuação enquanto docente, hoje já no ensino superior. Relatos dessa natureza, realizados de forma mais sistematizada e com reflexões, poderão auxiliar programas de formação continuada e revelar as necessidades do ensino, uma vez que podem evidenciar aspectos da prática docente ainda não revelados pelos docentes, bem como instigá-los a propor outros caminhos para a melhoria desta prática.

A sala de aula constitui-se em local complexo, no qual a singularidade dos docentes precisa ser olhada de forma cuidadosa, a fim de que sua atuação saia do campo privado e se encaminhe para a troca de experiências entre docentes e as boas práticas docentes se revelem no âmbito público. Diante disso, os relatos autobiográficos podem se tornar uma prática comum de divulgação destes saberes singulares, ainda não revelados, porém, tão importantes para a educação.

Nesta perspectiva, os estudos autobiográficos foram importantes para estabelecer essas relações de reflexão sobre minha vida acadêmica e profissional. o processo de formação é contínuo e a possibilidade de vivenciar outras práticas formativas, como especializações, cursos, mestrado e doutorado, fizeram com que tomasse consciência do meu papel social, de outras possibilidades de ensino, com reflexão sobre a ação, capazes de modificar as práticas docentes, desde que realizadas em processos sistematizados e contínuos de estudos e intervenções. 


\section{Referências}

BUENO, Belmira Oliveira. O Método autobiográfico e os estudos com histórias de vida de professores: a questão da subjetividade. Educação e Pesquisa, São Paulo, v. 28, n. 1, p. 11-30, jan./jun. 2002.

BUENO, Belmira Oliveira et al. Histórias de vida e autobiografias na formação de professores e profissão docente (Brasil, 1985-2003). Educação e Pesquisa, São Paulo, v. 32, n. 2, p. 385-410, mai./ago. 2006.

CONTRERAS, José. A autonomia de professores. São Paulo: Cortez, 2002.

CORRÊA, Thiago Henrique Barnabé. Os anos iniciais da docência em Química: da universidade ao chão da escola. 2013. 98 f. Dissertação (Mestrado em Educação) - Programa de Pós-Graduação em Educação, Universidade Metodista de Piracicaba, Piracicaba, 2013.

HUBERMAN, Michael. O ciclo de vida profissional dos professores. In: NÓVOA, António. (Org.). Vidas de professores. Lisboa: Porto Editora, 1992. p. 32-46. JOSSO, Marie-Christine. Caminhar para si. Porto Alegre: EDIPUCRS, 2010.

NÓVOA, António. (Org.). Os professores e sua formação. Lisboa: Publicações Dom Quixote, 1992.
PÉREZ-GÓMEZ, Angel. O pensamento prático do professor - A formação do professor como profissional reflexivo. In: NÓVOA, António. (Org.). Os professores e sua formação. Lisboa: Publicações Dom Quixote, 1992. p. 94-114.

SCHNETZLER, Roseli Pacheco. Concepções e alertas sobre formação continuada de professores de química. Química Nova na Escola, São Paulo, n. 16, p. 15-20, 2002.

SCHNETZLER, Roseli Pacheco. Investigação-ação e desenvolvimento profissional docente. In: REUNIÃO ANUAL DA SBQ, 26., 2003, Poços de Caldas. Anais... São Paulo: SBQ, 2003. p. 1-11.

SCHÖN, Donald A. Formar professores como profissionais reflexivos. In: NÓVOA, António. (Org.). Os professores e a sua formação. Lisboa: Publicações Dom Quixote, 1992. p. 77-91.

ZEICHNER, Kenneth M. A formação reflexiva de professores: idéias e práticas. Lisboa: Educa, 1993.

Recebido em: 02.01.2019 Aprovado em: 31.03.2019

Andréa Souza de Albuquerque é doutoranda em Educação em Ciências e Matemática pela Universidade Federal do Pará e Mestre em Educação pela Universidade do Estado do Pará - UEPA. Licenciada Plena em Pedagogia pela Universidade do Estado do Pará - UEPA. Pedagoga da Secretaria Municipal de Educação - SEMEC. e-mail: andasouza2014@gmail.com

Universidade Federal do Pará. Rua Augusto Corrêa 1 - Campus Universitário. Bairro: Guamá. Belém. CEP: 66075-110. (91) 3201-7112/9994-0644

Tadeu Oliver Gonçalves é Doutor em Educação Matemática, pela Universidade Estadual de Campinas (2000) Professor Titular. Universidade Federal do Pará. Instituto de Educação Matemática e Científica. Programa de Pós-Graduação em Educação em Ciências e Matemática. Linhas de Pesquisas: Formação de Professores Formadores de Professores de Matemática; Professores que Ensinam Matemática. e-mail: tadeuoliver@yahoo.com.br

Universidade Federal do Pará. Rua Augusto Corrêa 1 - Campus Universitário. Bairro: Guamá. Belém. CEP: 66075-110. (91) 3201-7112 